\title{
WEALTH AND INCOME EFFECTS OF NATURAL DISASTERS: AN ECONOMETRIC ANALYSIS OF HURRICANE HUGO
}

\author{
Paulo Guimaraes, Frank L. Hefner, and Douglas P. Woodward*
}

\begin{abstract}
Following natural disasters, many regions face substantial losses of wealth. However, some sectors experience temporary gains in economic activity as a result of insurance claims and other short-term income flows. This paper examines the economic gains and losses from Hurricane Hugo in South Carolina. The analysis is based on a multi-sector regional econometric model, which allows us to examine the state's economy "with and without" the storm. We first obtained estimates based on pre-Hugo period data. Then, we simulated the state's economy in the post-Hugo period based on the actual values of national economic variables during the reconstruction period-yielding the "without" storm estimates. We found that the income gains were neutral overall, despite a major surge in some sectors. Even in these sectors, the economic gain remained below the unreimbursed wealth loss. Thus, the catastrophe had a net negative economic effect.
\end{abstract}

\section{INTRODUCTION}

An irony of natural disasters is that although they destroy physical wealth, they often dramatically raise economic activity during reconstruction. Many urban and regional economies suffer immediate losses of wealth from physical catastrophes like hurricanes and earthquakes. However, some sectors of the economy experience temporary surges in income and employment that can be difficult to disentangle from other cyclical changes. For major disasters, these effects may last more than two years.

This paper examines the economic gains and losses from Hurricane Hugo, which struck South Carolina in September 1989. Twenty-five deaths were attributed to the hurricane, but other disasters have claimed many more lives. Yet Hugo, which directly hit the port city of Charleston and then moved rapidly inland across the state, was the most economically devastating storm in U.S. history. ${ }^{1}$

In the hurricane's wake, 24 of 46 counties in South Carolina were declared disaster areas. The affected areas encompassed urban and rural counties at different stages of economic development, including the diversified, densely populated Charleston metropolitan area; the coastal tourist and fishing communities of

\footnotetext{
*Professor, Faculdade de Economia, Universidade do Porto, and J.N.I.C.T.; Assistant Professor, Department of Economics, University of South Carolina; and Assistant Professor, Department of Economics, University of South Carolina, respectively. An earlier version of this paper was presented at the 1992 Meetings of the Southem Regional Science Association, Charleston, South Carolina, April 2-5, 1992.
} 
Georgetown and Horry counties; and inland agricultural counties like Marlboro, Williamsburg, and Clarendon that rank among the nation's poorest in terms of per capita income. Coastal counties were the most severely damaged, ravaged by high winds ranging up to 138 miles per hour and storm surges 20 feet above normal. The storm then swept across the eastern half of South Carolina. Counties more than 150 miles from the coast sustained extensive damage by high winds and rain. Overall, the official damage estimates amounted to $\$ 1.3$ billion in lost crops and timber, about $\$ 3.0$ billion in residences, and $\$ 1.0$ billion in commercial and industrial structures. The public infrastructure was also severely impaired, including some 18,000 miles of highways in South Carolina.

The immediate economic effects of any natural disaster are clearly negative, as was the case with Hurricane Hugo. The storm was an unanticipated shock to the state of South Carolina. It is well known from economic theory that shocks, from stock market panics to wars, affect economic behavior. Specifying how such surprises alter behavior depends on assumptions about rationality and long-term versus short-term expectations. The permanent income hypothesis, for example, suggests that consumers will spread the shock's wealth loss impact over a long time horizon. However, regional economic activity during the Hugo reconstruction period appeared to rise dramatically-especially for the retail and construction sectors. This rise was the obvious result of large and sudden financial flows to communities through disaster relief and insurance claims. The gain appeared to be so large, in fact, that some observers believed the storm engendered a net economic gain for the state. A year and a half after Hugo, budget analysts projected that South Carolina's overall income growth was sufficient to forestall the 1990-91 recession. Eventually, they admitted to being overly optimistic, misled by the storm's positive impact on the state's economic growth in the initial reconstruction period.

Econometric analysis can shed light on the wealth and income effects of natural disasters. Most disaster assessments project pre-disaster trends of selected economic variables and then determine the adjustment path to those trends as a measure of post-disaster impacts (for example, Friesema et al. 1979). One potential flaw with this method is that the same variables may be influenced by changing forces and events not associated with the disaster. A recession or war may have more impact on regional employment and income than a physical catastrophe.

This paper examines changes in economic activity following natural disasters from a new perspective. The assessment is based on a multi-sector econometric model of South Carolina. First, we estimated the model based on data for the pre-Hugo period. Then, we simulated the state's economy in the postHugo period, conditional on the observed values of national economic variables 
such as GDP and interest rate fluctuations during the reconstruction period. In this manner, we estimated the growth path that South Carolina would have taken had Hugo not occurred within the framework of the actual economic environment that did occur. Thus, we controlled for effects on the state's economy like the 1990-91 national recession and the Persian Gulf War. The effects of Hugo are measured by comparing the actual path of selected variables with the predicted path. We attribute any systematic deviations from the predicted path, especially when the variable lies consistently outside a 5 percent prediction interval, to the effects of the hurricane.

The rest of the paper is organized as follows. Section II describes the loss of wealth from the hurricane. In Section III, we explain our method for determining the disaster-induced changes in economic activity during the reconstruction period. Section IV presents our econometric simulations for changes in state income attributable to Hugo. A summary and conclusion follows in Section V. We suggest that a similar methodology may help urban and regional planners better assess natural catastrophes.

\section{PHYSICAL DAMAGE AND WEALTH LOSS}

This section examines the overall damage caused by Hurricane Hugo, focusing on the immediate physical losses or wealth effects. We will see that much of the loss of wealth in South Carolina was compensated by public and private disaster relief, but only about half the total.

Overall, the storm's physical damage has been estimated to be $\$ 6.272$ billion. ${ }^{2}$ These damages include losses to residences, commercial and industrial businesses, automobiles, utilities, port facilities, forestry, agriculture, military installations, and other government structures. Residences suffered the greatest damage, followed by forestry. The damage figures shown in Table 1 can be considered the loss of wealth effect.

Disaster areas potentially benefit from recovery efforts if there is a transfer of funds from outside the area that more than compensates for the losses. The evidence is not clear about the extent to which regional economic costs of physical disasters can be externalized to the larger economy (compare, for example, Chang 1984; Friesema et al. 1979). The important question is whether wealth induced by recovery assistance and reimbursements for structural damage are greater or less than the overall damage.

In South Carolina, reimbursements for structural damage totaled $\$ 2.891$ billion, which included federal flood insurance and private insurance claims paid. The distribution of these reimbursements, however, was uneven. Residences 
recovered approximately 45 percent of the damages through insurance claims. Commercial and industrial businesses fared much better. Of $\$ 1.0$ billion in physical damages, about 80 percent, or $\$ 829$ million, was paid in insurance claims. Forestry clearly was a loser. Against $\$ 1.2$ billion in damages to timber, it is estimated that only $\$ 150$ million was salvageable. ${ }^{3}$ In addition to insurance claims, part of the wealth lost due to the hurricane was recovered through public assistance. Public assistance amounted to $\$ 541$ million-most of it for military and other government rebuilding. In fact, public assistance fully compensated for damages to military and government property.

The estimate of physical losses not reimbursed through insurance or public assistance is also shown in Table 1 . Of the approximately $\$ 3.0$ billion in unreimbursed losses, about half can be accounted for by the forestry and agricultural sectors. In the storm's aftermath, then, agriculture and forestry were the most severely affected of the state's traditional industries.

TABLE 1

Estimates of Net Damages from Hurricane Hugo

(In Millions of Dollars)

\begin{tabular}{lcccc}
\hline \hline & & & & \\
& & \multicolumn{2}{c}{ Reimbursements } & \\
\cline { 2 - 4 } Category & Damages & Insurance & $\begin{array}{c}\text { Public } \\
\text { Assistance }\end{array}$ & $\begin{array}{c}\text { Unreimbursed } \\
\text { Loss }\end{array}$ \\
\hline Residences & $\$ 2,960$ & $\$ 1,349$ & $\$ 22$ & $\$ 1,589$ \\
Commercial/industrial & $\$ 1,029$ & $\$ 829$ & $\$ 0$ & $\$ 200$ \\
Federal flood insurance & & $\$ 365$ & $\$ 0$ & $(\$ 365)$ \\
Autos, misc. & $\$ 215$ & $\$ 182$ & $\$ 0$ & $\$ 33$ \\
Utilities & $\$ 197$ & $\$ 0$ & $\$ 74$ & $\$ 123$ \\
Ports authority & $\$ 17$ & $\$ 16$ & $\$ 1$ & $\$ 0$ \\
Forest & $\$ 1,031 *$ & $\$ 0$ & $\$ 0$ & $\$ 1,031$ \\
Agricultural structures & $\$ 294$ & $\$ 0$ & $\$ 0 * *$ & $\$ 294$ \\
Agricultural crops & $\$ 87$ & $\$ 0$ & $\$ 2$ & $\$ 85$ \\
Charleston Naval Base & $\$ 250$ & $\$ 0$ & $\$ 250$ & $\$ 0$ \\
Shaw Air Force Base & $\$ 50$ & $\$ 0$ & $\$ 50$ & $\$ 0$ \\
Other government & $\$ 142$ & $\$ 0$ & $\$ 142$ & $\$ 0$ \\
\hline \multicolumn{1}{c}{ Total } & $\$ 6,272$ & $\$ 2,741$ & $\$ 541$ & $\$ 2,990$ \\
\hline Net of estimated & & & & $\$ 1$ \\
\hline
\end{tabular}

* Net of estimated value of salvaged timber.

** Farmers received some funds from FEMA, which are included under reimbursements for residences.

Source: S.C. Budget and Control Board (1991). 
The other net losses were mostly shouldered by residences, not businesses or government institutions. The unreimbursed loss of wealth to residences remains a subtle problem that no doubt will influence the state's economy. Savings used to rebuild homes carry an opportunity cost: the money could have been spent to enhance communities beyond their existing base of wealth. Instead, it will be used to bring communities back to where they were before the storm, or the region must accept some of the damage as a loss. Yet this loss does not necessarily pose a problem in terms of the daily functioning of the economy-the activities of businesses and consumers. It should only be seen as a one-time decrease in the state's wealth.

The effects of wealth losses on individual economic behavior are difficult to gauge a priori. Economic theory suggests that shocks to wealth holdings should affect consumption patterns. However, theory also suggests that if the shock is viewed as transitory, then the effect on lifetime income may be negligible; consequently, the consumption effects would also be negligible. The problem is more complicated when the loss of wealth is physical, not financial. Here the problem is to identify opportunities lost by the destruction of an economy's stock. One could simulate what would have happened had this loss not occurred. Such a simulation is in the vein of "what-if" modeling-a good use for regional econometric models. The difficulty with empirically measuring the long-term behavior change from physical wealth destruction is that there is no quantifiable variable that captures the expectations imbedded in wealth. Even if a model could accurately incorporate expectations, the long-term loss of wealth effects from transitory shocks may be hard to detect because they are likely to be smoothed over many years.

What we can do more accurately is analyze the short-term response of the economy. Some sectors clearly benefit from positive spending flows for reconstruction, much of it from outside the region. In fact, these income flows stabilize the economy after the initial shock. Yet the income surge is especially pronounced in a few sectors and produces surprising effects even after two years, as we explain in the next two sections.

\section{MODELING ECONOMIC RECONSTRUCTION}

This section explains the method we used to assess post-Hugo economic gains and losses, based on simulations run on an econometric model of South Carolina. Ellson, Milliman, and Roberts (1984) noted that most studies of disasters suffer from methodological deficiencies. Typically, researchers adopt one of two methods: a "before-and-after" comparison or a "deviation from trend" 
analysis. The problem with before-and-after analysis is that it is hard to pinpoint how much of the "after" changes should be attributed to the disaster. One could assume that nothing else of significance is happening in the economic environment, but this assumption is rarely justified. This type of analysis often relies on ad hoc explanations of the post-disaster period. For example, in a Hugo assessment report delivered to the governor of South Carolina, it was noted that "manufacturing employment dropped by 1,600 but most of these jobs were not believed to be related to Hugo, but rather to an overall decline in manufacturing nation-wide. ${ }^{4}$ The report concluded that "on balance, the employment survey reported that new jobs offset those lost because of Hugo" (South Carolina Budget and Control Board 1989, 6). Yet without an appropriate methodology, the "before and after" type analysis can never sort out how many jobs were lost to Hugo and how many were lost because of a downturn in the economy.

Simple time trend disaster analysis suffers from similar problems. Typically, a trend line is estimated from data before the disaster and then projected for the aftermath. Deviations of observed values from projected values are attributed to the catastrophe. In what is sometimes called "interrupted time-series design," the trend must first be determined by some reasonable technique. Friesema et al. (1979) suggested several possible approaches, including ordinary least squares estimation and ARIMA modeling. However, these techniques cannot circumvent the basic problem with simple time-trend disaster analysis: it implicitly assumes the local economy would have continued to follow the trend before the disaster, independent of other exogenous forces. This approach had obvious flaws in analyzing Hurricane Hugo. Within a year of Hugo, South Carolina experienced additional economic uncertainties following the Iraqi invasion of Kuwait and the contractionary pressures of the national recession that started in mid-1990. Using standard before-and-after type comparisons, these changes would be included in the measurement of the Hugo aftereffects.

Hence, a methodology was needed to separate post-Hugo fluctuations attributable to the storm from other exogenous forces. Only by isolating the hurricane's impact can we reasonably conclude that this specific shock caused any deviations from trend. In this connection, a regional econometric model proved to be a valuable tool in the analysis of Hugo. Without a structural econometric model, it would be hard, if not impossible, to test the null hypothesis that the disaster had no effect on the regional economy. We used the following methodology. First, the coefficients of all variables in an econometric model of South Carolina were estimated up to the second quarter of 1989 (just prior to the hurricane). With the estimated coefficients from pre-Hugo data, we then projected the economy after Hugo. In effect, we froze the structure of the South Carolina economy just before Hugo. Then, by incorporating post-Hugo national variables, 
we controlled for the exogenous factors that impinged on the state's economy. Thus, we were able to develop a more accurate measure of Hugo's true impact, avoiding the problems that arise when one mixes the impact of a disaster with the impact of national business cycles and other changes. This follows Ellson, Milliman, and Roberts' (1984) suggestion that the correct comparison to make is "with-and-without," not "before-and-after." For example, our base line projection simulates the South Carolina economy without Hugo and with the recession. The actual track that is observed represents South Carolina with Hugo and with the recession.

In a similar manner, Chang (1983) proposed using an estimated equation to forecast tax revenues for the city of Mobile after Hurricane Frederick. Chang's method is in the spirit of with-and-without comparisons. However, his independent variable-local retail sales-is itself a dependent variable and fluctuates both with the effects of the hurricane and with exogenous shocks not related to the hurricane. Since our model is a multi-equation model that is estimated and simulated simultaneously, our method not only accounts for exogenous shocks independent of Hugo, but also for the endogeneity of the South Carolina-specific variables.

The econometric model used in the analysis was developed by the Division of Research, College of Business Administration at the University of South Carolina. Since 1984, the South Carolina Quarterly Model (SCQM) has projected employment, income, demographic, finance, retail, fiscal, and construction variables for South Carolina on a quarterly basis. The SCQM has had a good track record over the years. An internal evaluation performed in 1989 found that the average mean absolute percentage error for all variable forecasts (i.e., one quarter to eight quarters ahead forecasts) does not exceed 2.5 percent.

The SCQM is a variant of the regional top-down approach. ${ }^{5}$ The state model is driven by 20 national variables, which are projected under alternative national scenarios by FAIRMODEL, a well-known U.S. macroeconomic forecasting model. In the present analysis, national variables were set to their actual values, so forecasts from the national model were not needed. Overall, the SCQM consists of 90 equations, of which 71 are behavioral and 19 are identities.

Figure 1 is a flow chart that depicts how the national model feeds into the seven basic blocks of the state econometric model. The figure also shows that the blocks have a high degree of simultaneity. These interrelated blocks are briefly described next. ${ }^{6}$ 
FIGURE 1

South Carolina Quarterly Model Flow Chart

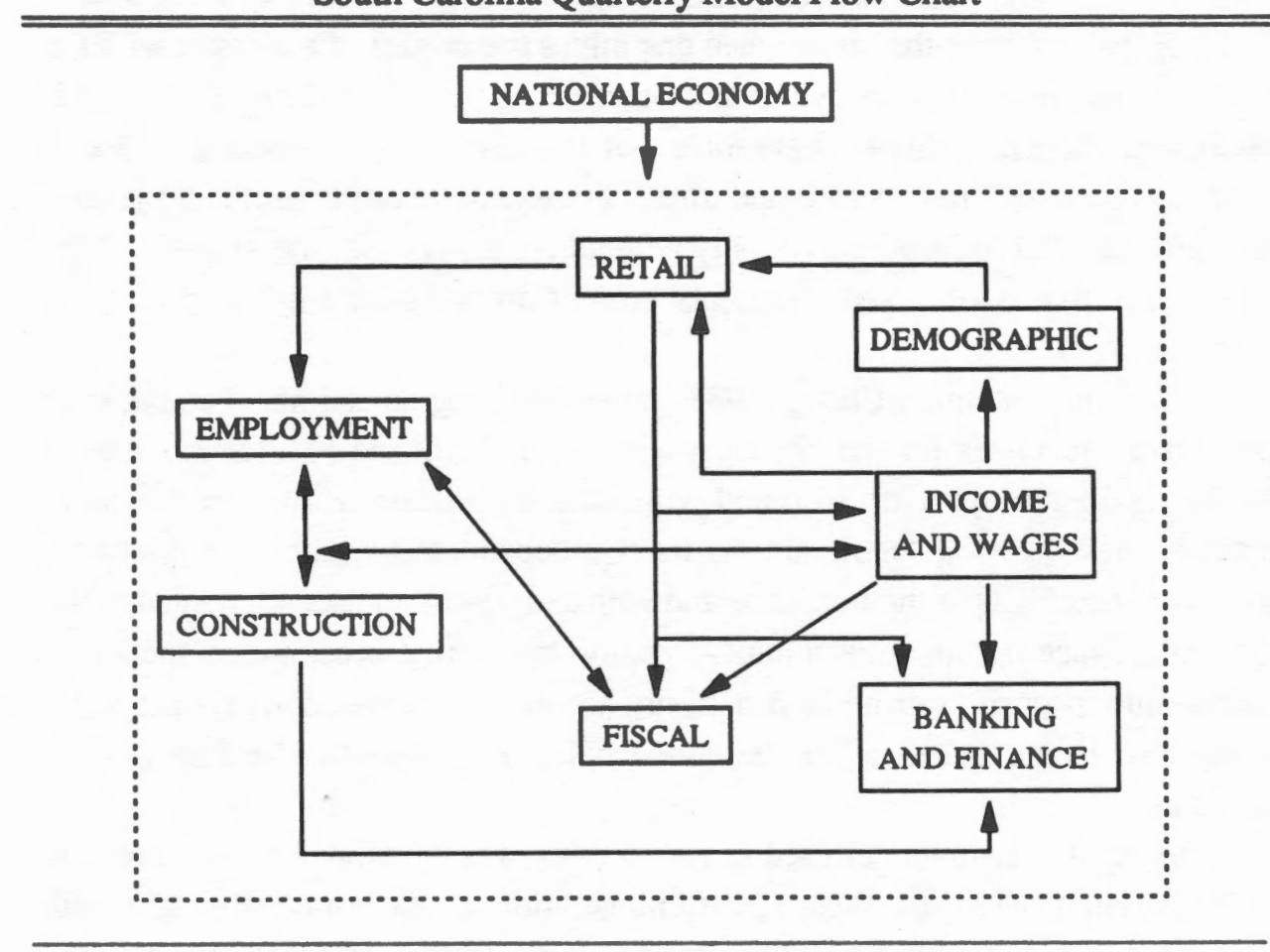

\section{The Employment Block}

In the SCQM, employment is forecast for all major sectors of the economy (manufacturing, wholesale and retail trade, and the like), with additional forecasts for manufacturing industries at the two-digit SIC level. The generalized form of the employment equations can be interpreted as reduced forms of an inverse production function. They are specified as follows:

$$
E M P_{j, t}=f\left(Y_{j, t} Z_{j, t} E M P_{j, t-1}\right),
$$

where $E M P_{\mathrm{j}, \mathrm{t}}$ is the employment at sector $j$ in quarter $t, Y_{\mathrm{j}, \mathrm{t}}$ stands for sectorspecific regional economic activity variables, and $Z_{\mathrm{j}, \mathrm{t}}$ represents sector-relevant national economic activity variables. Thus, the specification of the employment equations varies across industries. For example, the equations in the manufacturing sector, which are mostly regional export-oriented industries, are primarily linked to national variables; local-oriented service industries are more heavily linked to regional variables. 


\section{The Income and Wage Block}

The income and wage block projects nominal income for the major industries as well as for transfer payments, personal contributions to social insurance, and dividends, interest, and rents. This block plays a pivotal role in the model because many of its variables determine those in other blocks. In addition, the income variables are affected by activity elsewhere in the model. The general structure of the income equations is similar to that described above for the employment block. Besides the income variables, average weekly manufacturing earnings are also specified. They are a function of national weekly earnings, a trend variable, and the South Carolina unemployment rate (a proxy for general market labor conditions).

\section{The Demographic Block}

In this block, stochastic equations are estimated for the state's population, the state's unemployment rate, and total employment, with the labor force and the number of unemployed determined as identities. Population is related to real income growth and a trend variable. The unemployment rate is determined by its national counterpart and by a lagged dependent variable.

\section{Other Blocks}

The model includes four other smaller blocks: construction, banking and finance, fiscal, and retail. The construction block forecasts residential construction (single and multi-family housing starts) and nonresidential construction (permits, in square footage). The banking and finance block consists of four stochastic equations for loan activity (individual, real estate, commercial, and industrial) as well as time and savings deposits. These variables are related to national interest rates, real income growth, and other regional variables. The fiscal block projects revenues by major categories. Finally, the retail block consists of a single equation for retail sales, which is linked to population and income.

Many states and localities have econometric models similar in structure to the SCQM. While typically employed as short-term forecasting tools, all wellspecified regional models can be used as tools in the analysis of natural disasters in the same manner as in this analysis. The income-wage and employment blocks proved to be the most important, for reasons made clear in the next section.

Along with the model's projections for South Carolina variables, we generated a 5 percent confidence prediction interval for the post-Hugo period. ${ }^{7}$ The storm's impact was defined as the deviation from the base line simulation or, 
in a more restrictive case, from the bounds of the forecast interval. If a variable is consistently above or below the forecast, then the deviation is evidently not random. Alternatively, if a variable consistently tracks outside of the confidence interval, we claim that this is the result of Hugo with a greater degree of certainty, since the model incorporates the changes caused by possible prediction error.

\section{INCOME AND EMPLOYMENT EFFECTS}

Employing the methodology explained in the previous section, we found that South Carolina's total personal income suffered a major drop in the third quarter of 1989 due to the hurricane. In fact, South Carolina was the only state with a decline in personal income during 1989, according to the official statistics released by the U.S. Bureau of Economic Analysis (BEA). If the effects of the damage caused by the hurricane were excluded, personal income would have increased 9.4 percent in the state (U.S. Department of Commerce 1990).

Often regions hit by natural catastrophes experience perverse changes in personal income. To a large extent, however, the personal income effect is an accounting, not an economic, artifact. The fall in the official BEA state personal income series stems primarily from an estimated loss in rental income. For as defined by the BEA, total personal income is comprised of dividends, interest, and rent payments, in addition to wages and salaries (the major portion of the total personal income). Included in the rent calculations are imputed rents, i.e., rents attributed to homeowners for the use of their own home. Uninsured losses to private homes are deducted from imputed rents. The decline in South Carolina's personal income in the third quarter of 1989 largely reflected damage to structures caused by the hurricane and figured in the calculation of imputed rental income.

Therefore, we believe that aggregate state personal income reported by the BEA is not a good reflection of Hugo's short-term economic effects. The deduction of uninsured losses from imputed rents seems to confuse the difference between a stock and a flow concept, i.e., between the wealth and income effect. Wages and salaries in the third quarter of 1989 did not drop as a result of Hugo. The storm struck in the last nine days of the quarter, which makes the drop in income seem more of a statistical measurement problem than a real income loss. By the first quarter of 1990, the historical track coincides with the base line simulation. In fact, total state personal income stayed within the forecast interval after the initial drop. There was no sign of a lasting effect, positive or negative.

Our analysis also showed that total employment in South Carolina was not affected by Hugo. Not only did the historical values of employment stay within the 5 percent prediction interval, but the predicted values remained fairly close to 
the observed values. In the aggregate, these employment and income effects make sense for the time period. In the second quarter of 1989, the South Carolina unemployment rate was at the lowest point in 16 years (4.2 percent). With the economy approaching full employment, any effects of a disaster would primarily be seen in the sectoral composition of jobs and income, not the aggregate figure. ${ }^{8}$

The specific sectors most influenced by the storm were construction, agriculture and forestry, retail trade, and transportation and public utilities. Not surprisingly, the hurricane's major impact was in the construction sector. Construction income is shown in the upper half of Figure 2, where the actual numbers can be seen to rise systematically above the pre-Hugo path after one quarter. In addition, construction income exceeded the 5 percent confidence prediction interval around our base line projections from the fourth quarter of 1989 to the first quarter of 1991 . During those six quarters, Hugo added $\$ 360.6$ million to construction income if we just consider the deviation from the upper bound. This effect is the result of the hurricane, taking account of possible prediction error. The construction income effect is $\$ 486.5$ million if we consider the positive deviation from the base line running between the two bounds depicted in Figure 2 .

One unexpected result to emerge from the analysis is the length of time the hurricane affected the economy. Note the path of construction income beginning in the third quarter of 1991. As Figure 2 depicts, there is a negative economic aftershock two years after the disaster. Apparently, residents and businesses undertook construction projects that may have been part of normal maintenance, along with storm damage repair, which boosted construction income in the quarters following the disaster but dampened it in later quarters. ${ }^{9}$

The income deviations accounted for by Hugo, both positive and negative, are tabulated in Table 2. The absolute deviation is the difference between the forecasted value and the observed value. The above-normal deviation is the difference between the observed value and the 5 percent prediction interval. The length of the income effect is also given in Table 2. For the period examined, the net effect of the hurricane on construction income was about $\$ 400$ million, much larger than any other sector.

In addition to income, the model forecasts state employment levels by sector. The simulation results indicated that construction employment, like income, shot well above the base line. Overall, if we measure the reconstruction effect from the base line, Hugo accounted for an extra 8,200 jobs during the first year of the reconstruction period-about 8.5 percent of the sector's employment base. By the second quarter of 1991, however, the lingering effects of the reconstruction activity had tapered off as the levels of employment began to converge to the base line forecast. During the second half of 1991, construction jobs fell below the 


\section{FIGURE 2}

Income Effects: Construction and Agriculture, Forestry, and Fisheries
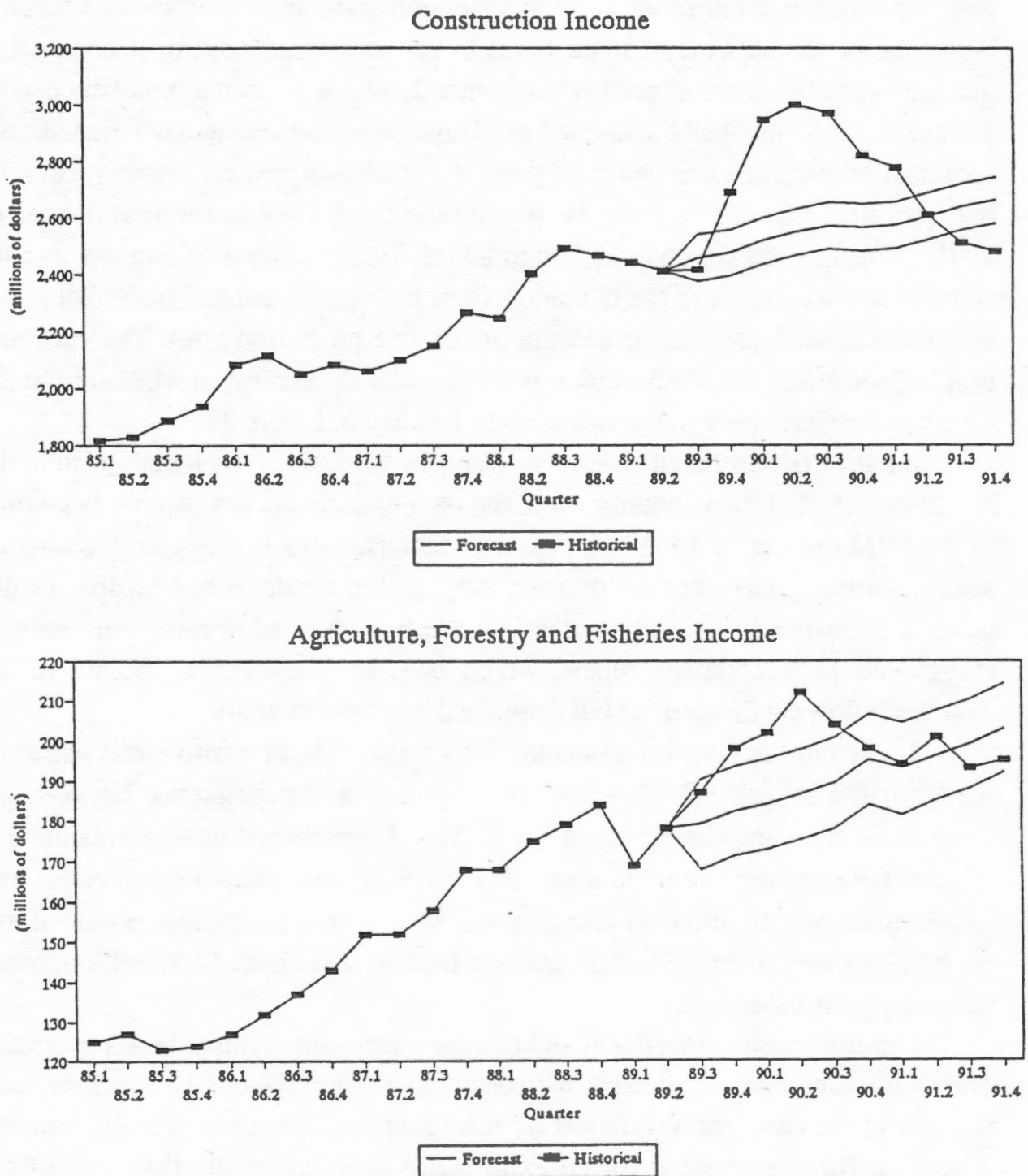

Source: South Carolina Economic Forecasting Service. 
base line, but they fell outside the prediction interval by only 200 in the fourth quarter.

Next, consider the income effect in the agriculture and forestry sector. As we discussed in Section II, this sector suffered a large loss of wealth from the hurricane. However, as the lower graph in Figure 2 shows, there was a post-Hugo income gain above the predicted base line. The net deviation from the base line was $\$ 18.8$ million. The deviation outside of the prediction interval was $\$ 7.2$ million (see Table 2). Anecdotal evidence strongly suggests that most of the income gain could be attributed to a massive salvage effort in forestry. Trees that would have been harvested over many years were cut by Hugo and sold as pulpwood at bar-

\section{TABLE 2}

Estimated Income Effects

(In Millions of Dollars)

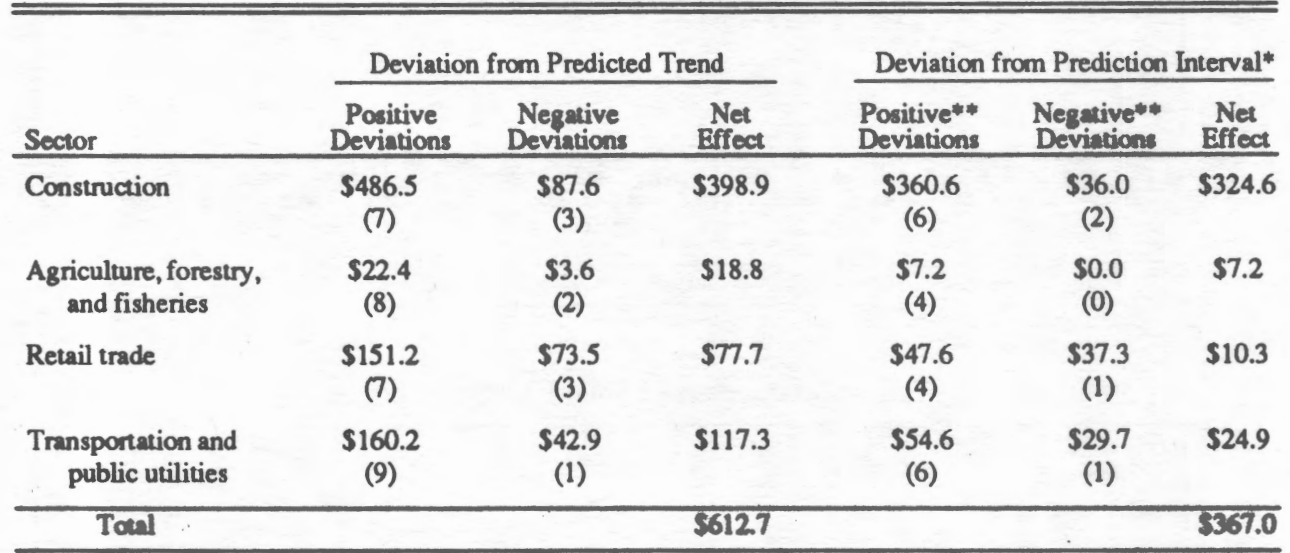

* Prediction interval computed for a 95 percent confidence level.

** Positive and negative deviations taken respectively from the upper and lower bounds.

Note: The values in parentheses represent the number of quarters for the detected deviations.

Source: South Carolina Economic Forecasting Service.

gain prices. However, the income gain of $\$ 18.8$ million was much smaller than the estimated wealth lost ( $\$ 1.5$ billion) in this sector.

Another major sector affected by Hugo was retail trade. The income effect for retail trade is shown in the upper half of Figure 3. First, we observe a drop below the prediction interval, followed by a quick rebound that shoots the actual path of the variable above the upper bound. Overall, the model estimates show that net retail trade income increased by $\$ 10.3$ million (counting the deviation from the prediction interval) or $\$ 77.7$ million (measuring the change from the base line). 
FIGURE 3

Income Effects: Retail Trade and Transportation and Public Utilities

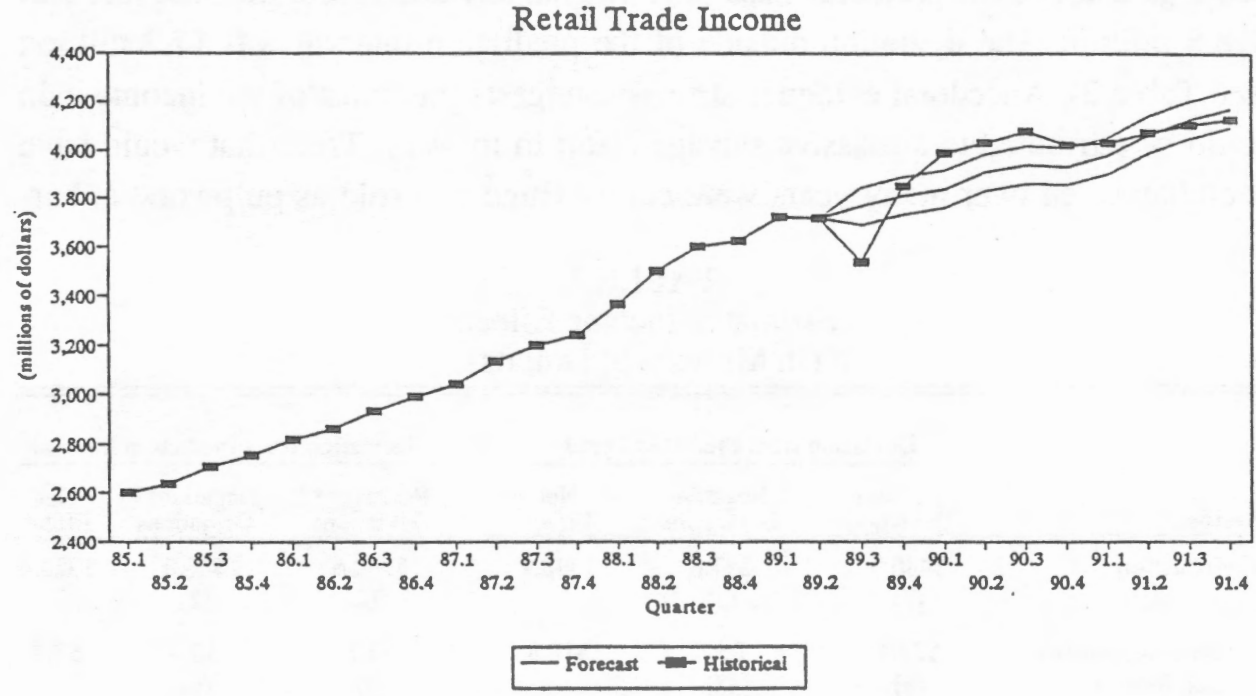

Transportation and Public Utilities Income

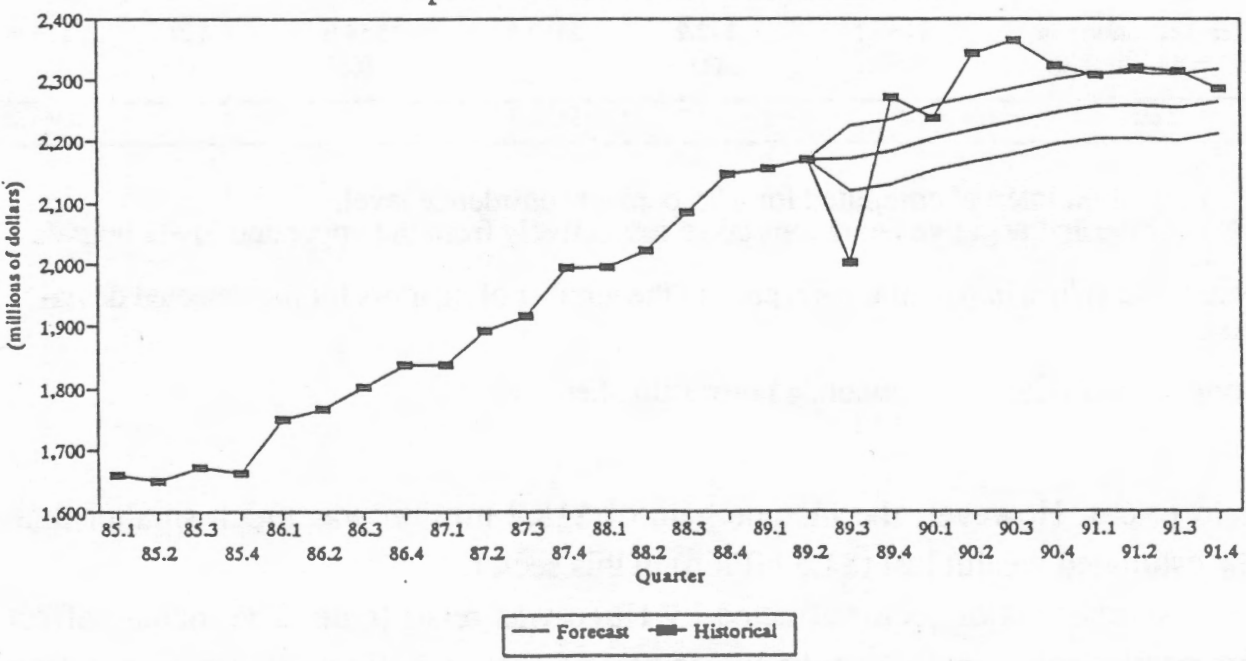

Source: South Carolina Economic Forecasting Service. 
Finally, the rebuilding effort concentrated on repairing the infrastructure damaged by the storm. As a result, income in the transportation and public utilities sector followed a pattem similar to retail trade. In the third quarter of 1989 , income fell sharply below the lower bound; then it bounced back quickly in the fourth quarter of 1989, rising above the upper bound for six consecutive quarters (see Figure 3). During those six quarters, the total positive deviation from the prediction interval was $\$ 54.6$ million. Including the one quarter drop below the prediction interval, the net effect beyond the prediction interval amounted to $\$ 24.9$ million. The total net effect measured by the deviation from the base line amounted to $\$ 117.3$ million.

\section{v. CONCLUSION}

In the uncertain period that follows the shock of a natural disaster, it is often difficult to discern what the effects will be on the economy or how long it will take to return to normal conditions. As the data become available, analysts often rely on before-and-after comparisons to assess the economic consequences. However, by simulating a regional econometric model, it is possible to examine a disaster's economic effects while holding all other conditions constant.

This paper presented results of such a "with-and-without" analysis. Based on the econometric analysis, two alternative paths of the state's economy were compared: (1) projected economic activity for the year following the hurricane based on national trends during the recovery period and historical trends in South Carolina before the hurricane; and (2) the actual level of economic activity with the hurricane's effect included. Through this analysis, we found that the income gains were neutral overall, despite a major surge in construction, retail, and other sectors. In one of the most affected sectors of South Carolina, agriculture and forestry, the income gain remained below the unreimbursed wealth loss. Thus, we maintain that the catastrophe was not a positive economic force. The result is true whether we use the deviation from the base line or from the prediction interval as the reference point for the "without" Hugo economy.

This paper emphasized that some sectors of the South Carolina economy surged during the Hurricane Hugo reconstruction period. The impetus for this growth was the infusion of billions of dollars from insurance and public assistance. Although the money did not compensate for damages, the rebuilding effort created a short-term boom before the economy returned to its normal growth path. The major effects were distributional. The sectors that benefitted most were construction, agriculture and forestry, retail trade, and transportation and public utilities. 
This paper also emphasized the distinction between the wealth and income effects. These effects relate to the changes in the stock and flow variables. The regional econometric model was used to evaluate the flow variables, but some data, most notably the BEA personal income figures, may confound this distinction. We discussed the problem of incorporating imputed rents in the personal income data. According to federal income statistics, South Carolina sharply reversed the steady gains in per capita income growth before Hugo, dropping to last place in the nation during the third quarter of 1989. We have anecdotal evidence that out-of-state retail establishments who were considering opening branches in South Carolina reevaluated those decisions based on the reported personal income drop. Because official income statistics can be misleading if taken at face value, immediate research into sorting out the stock and flow measures of disaster damage should be conducted after any similar shock.

There is also evidence that insurance compensation often motivated recipients not only to rebuild, but to dip into past savings in order to expand and improve the damaged property. In South Carolina, there were cases of private homeowners, as well as small businesses, rebuilding in this manner. This may have dampened construction activity two years later. Clearly, there is a need to monitor a disaster's effects over a relatively long period to determine when the economy returns to normal.

A better understanding of the opportunity cost of wealth losses is another line of needed research. Yet there may be long-term economic impacts that cannot be measured adequately. For example, some structures such as bridges may have been weakened by the stresses incurred by the strong winds. These weaknesses may not appear for some time in the future, which is when the expenditures for their repair will occur.

Regional shocks are difficult to assess accurately. Our research points to the need for continued analysis to determine the impact of changes in the total wealth in a region. Nevertheless, we have found that regional econometric modeling provides a useful tool to segregate economic changes caused by a disaster from those caused by other exogenous factors impinging on the economy.

\section{ENDNOTES}

1. This paper was written before Hurricane Andrew, which was economically more devastating. For analysis of Andrew, see West and Lenze (1993).

2. The basic data on the loss of wealth are from South Carolina Budget and Control Board (1991). 
3. The S.C. Budget and Control Board (1991) estimated the amount of salvageable timber. However, to date there are no estimates of the amount of downed timber that was actually recovered. Furthermore, the Budget and Control Board's report categorizes this estimate as a reimbursement. Salvaged timber constitutes an abnormal income effect that should appear in our estimates of the income effect in the agriculture and forestry sector.

4. The statement can be found in South Carolina Budget and Control Board (1989).

5. Bolton (1985) provides a basic flow chart of the generic regional econometric models and reviews the more well-known regional models.

6. A more detailed description of the model, including the complete specification for each equation, is available from the authors.

7. The prediction error incorporates the error from both the estimated coefficients and the disturbance term.

8. We also found that general revenue for the state remained within the 5 percent prediction interval after Hugo. State analysts concurred that Hugo had no appreciable net effect on state revenues, with gains from income and sales taxes on building materials offset by casualty loss claims against income taxes (State Budget and Control Board 1991). Thus, we conclude that there was no measurable state fiscal impact from Hugo. We do not deny that there may have been fiscal effects in hard-hit urban areas like Charleston. For an analysis of urban fiscal effects following Hurricane Frederick on the tax revenues of Mobile, Alabama, see Chang (1983).

9. The 1991 erratic movement in construction income evident in Figure 2 is not the result of the 1990-91 U.S. recession. The national downtum of the early 1990s has already been accounted for in the "without Hugo" trend line, which was forecast with actual national conditions throughout the period. At any rate, the construction "bust" was modest in South Carolina, particularly in comparison with the Northeast, Southwest, and California. Moreover, new construction started falling during 1988-89 (before Hugo) and continued through 1991. In fact, the 1991 drop in residential construction was modest-only 4.8 percent-compared with 15.6 percent in 1989 and 18.6 percent in 1980. Nonresidential construction fell 6.8 percent, compared with 18.4 percent in 1989 and 23.2 percent in 1982.

\section{REFERENCES}

Bolton, Roger. "Regional Econometric Models." Journal of Regional Science 25 (1985): 495-520. 
Chang, Seemon. "Disasters and Fiscal Policy: Hurricane Impact on Municipal Revenue." Urban Affairs Quarterly 18, no. 4 (1983): 511-523. . "Do Disaster Areas Benefit from Disasters?" Growth and Change 15, no. 4 (October 1984): 24-31.

Dacy, Douglas C., and Howard Kunreuther. The Economics of Natural Disasters: Implications for Federal Policy. New York: The Free Press, 1969.

Ellson, Richard, Jerome Milliman, and R. Blaine Roberts. "Measuring the Regional Economic Effects of Earthquakes and Earthquake Predictions." Journal of Regional Science 24, no. 4 (1984): 559-579.

Friesema, H. Paul, James Caporaso, Gerald Goldstein, Robert Lineberry, and Richard McCleary. Aftermath: Communities After Natural Disasters. Beverly Hills: Sage Publications, 1979.

South Carolina Budget and Control Board. Division of Research and Statistical Services, Office of Economic Research. "Economic Impact of Hurricane Hugo." Columbia, S.C., January 15, 1991. . "Second Post-Hugo Status Report." Columbia, S.C., December 6, 1989.

U.S. Department of Commerce. U.S. Department of Commerce News. Washington, D.C., January 23, 1990.

West, Carol, and David Lenze. "Natural Disaster and Recovery: An Assessment of Regional Data and Impact Methodology in the Context of Hurricane Andrew." Paper presented at the Southern Regional Science Association Meetings, Tysons Corner, Virginia, April 1-4, 1993. 